Psychological Medicine, 1988, 18, 11-13

Printed in Great Britain

\title{
EDITORIAL
}

\section{Immune reactions and mental disorders ${ }^{1}$}

Is the immune response altered in mental illness? Conversely, does an immune response affect mental function? Are any observed changes (both mental and immunological) the result of aetiological relationships?

The answers to these questions are far from straightforward. The field is complex and evidence from immunological, psychiatric, psychological and neuroendocrinological studies is still scarce and fragmentary. On the other hand, studies aimed at finding a linear causal relationship are perhaps inappropriate for biological interactions between such multivariate systems as the immune system and the central nervous system (CNS) (Bennette, 1969).

There are, however, good reasons to draw a parallel between the two systems and to postulate links between them. Both serve functions of adaptation and defence, and both intervene in the relationship between the individual and the environment. The CNS, the site of emotions, personality and ego defences, shares the same responsibilities as the immune system which is that of discriminating between self and non-self and protecting the integrity of the self against intrusions of non-self. Both systems have flexibility and a diversity of responses that incorporate principles of recognition, learning, memory and transmission of information.

The immune response can be modified by the state of mind. This is shown by studies with hypnosis (Black et al. 1963), meditation (Smith et al. 1985) and conditioning (Ghanta et al. 1985). Psychological experiments in animals have shown that early experiences like stress and separation can influence the immune response later in life (Solomon et al. 1968; Laudenslager et al. 1983). Also, direct intervention in the CNS modifies immune response. For example, experimental hypothalamic lesions in animals decrease lethal anaphylaxis (Stein et al. 1976). A link in the converse direction is shown by studies with implanted electrodes which have demonstrated direct regulation of the hypothalamus by an immune response (Besedovsky et al. 1983).

From an accumulation of data such as this, a feedback loop between the hypothalamus and the immune system has been suggested (Solomon \& Amkraut, 1984). The neuroendocrine system, also involved in the process of adaptation, has been proposed as the link and common path between the CNS and the immune system. The interaction of these three systems has been supported by studies on stress (for review, see Farrant \& Perez, 1987) and by the close and often interdependent relationship between the CNS, the hypothalamus-pituitary-adrenal axis and the immune system.

The potential for links between the CNS and the immune system is further suggested by the presence of receptors for neuro- and other hormones on lymphocytes. Many of these hormones are able to modify lymphocyte function (see Farrant \& Perez, 1987). Bohus (1984) has proposed that an old model be extended to the immune system. 'Neural messages' are translated into 'hormonal messages' which then affect various target organs, including the adrenal gland and hence the lymphocytes of the immune system. Information from target organs can feedback to the CNS, closing the cycle of homeostatic adaptive interactions.

What are the implications of these interactions for mental illness? The best studied and most clear evidence comes from investigations done on stress. Stress is known to have a direct effect on behaviour, neurohormone release and immune response (see Farrant \& Perez, 1987). It is important, however, to avoid a simplistic notion of stress as being the 'cause' of disease, but look rather at its effect in influencing the expression of disease in the interaction between personality and

\footnotetext{
' Address for correspondence: Dr M Perez, Frimley Park Hospital, Portsmouth Road, Camberley, Surrey.
} 
biology of the host. The circumstances where stress is imposed, the environmental, emotional and social background, as well as the avenues available to the individual for solving or adapting to the situation have all relevant implications in the responses at behavioural, neurochemical and immune response levels. The exact nature of the stress, timing and exposure also influence immune responses. In general, acute stress seems to decrease immune response, but after a period a process of adaptation can occur, with immune response gradually returning to normal. In certain circumstances, however, stress appears to enhance the immune response (Cooper et al. 1979).

The emotional and behavioural response to stress is anxiety, both an adaptive and also a pathological response often involved in the pathogenesis of mental illness. Cortisol emerges as one of the relevant hormonal factors to account for changes in behavioural as well as in immune response. There is a direct association between the severity of anxiety and depressive symptoms and levels of cortisol (Kronfel et al. 1983; Meltzer et al. 1984). There is also a direct relationship between high levels of cortisol and a decrease in the immune response (Fauci \& Dale, 1974). Cortisol enhances the activity of the serotonergic neurotransmitter pathway which is involved in the development of anxiety and depressive symptoms (Cowen \& Anderson, 1985) and also decreases immune response. These relationships may account for the decrease in immune competence and the increased susceptibility to diseases, both in depression and following life events like bereavement (Bartrop et al. 1977). Although the connection 'stress-cortisol' seems to play an important role, other neurohormonal mechanisms may also be involved.

Depressive illness may occur in the absence of obvious precipitants or stress. Interestingly, the association of stress preceding depressive illness tends to occur within six months (Paykel et al. 1969); similarly, the susceptibility to certain somatic diseases, for example, cancer and some infections, increases within the first six months after the death of the spouse (Jacobs \& Ostfield, 1977). Whether decreased immunity following infections, or other somatic disorders involving the immune system, can trigger a depressive illness by increasing cortisol levels, is still a matter to be considered. The relationship between Cushing's disease and depression is well known.

There is, however, evidence linking depression with somatic diseases, such as autoimmune thyroiditis, allergy, diabetes, asthma, multiple sclerosis and rheumatoid arthritis (see Farrant \& Perez, 1987). Depression associated with AIDS is a more complex phenomenon, since in addition to the reactive emotional element there is sometimes direct invasion of the CNS by the virus.

In cancer, studies have suggested an association with depression. Epidemiological work has shown that there is an increased risk in developing cancer within the first six months after bereavement. The theory of immune surveillance as a physiological means of dealing with malignancy involves cell-mediated immunity, and it has been shown that depression in cancer appears to be associated with an impairment of cell-mediated immunity (Kronfol et al. 1982; Linn et al. 1982).

The relationship of the immune system to other psychiatric disorders, e.g. major psychoses, is less clear (Rodnight, 1986). Early studies linking schizophrenia with an autoimmune disorder could not be confirmed by Knight (1982).

At first sight, a decrease in immune response following stress appears paradoxical. It may, however, be a protective mechanism against an excessive defence, that is, against loss of control in the immune response (Munck et al. 1984). A depressive illness appears equally paradoxical in the context of stress, unless depression is also considered as a protective mechanism of withdrawal from increasingly dangerous and noxious levels of anxiety. In this light, depression then becomes part of the adaptive response of the individual to the environment.

In this adaptation, three independent yet closely related systems - the CNS, the neuroendocrine and the immune system - are involved. It has been suggested (Bennette, 1969) that in order to achieve meaningful homeostatic balance, these systems must be in constant dialogue at different levels. In order to maintain biological identity, however, each system must behave in a state of functional subordination. The CNS acting as the major controller, translator and integrator, of stimuli arriving from the environment would also act as the controller of the adaptive response to the internal environment. 
Breakdown of communication at different levels can lead to alienation (non-adaptive) (Ballieux, 1984). In cancer, for example, the failure of the lymphocytes to recognize changes in cellular identity may lead to an anonymity of the cancer cells, and hence to their survival. Thus, alienation at the cellular level implies loss of relevant information indispensible for organizational control. This can be paralleled at the emotional level by lapses in communication (conscious or unconscious), which may lead to a denial of stress or internalization of emotions, thus exposing the individual to further stress.

Much more collaborative work is needed in this field between psychiatrists and immunologists, but the relationship between immune reactions and mental disorders should not now be ignored.

MARGARITA PEREZ AND J, FARRANT

\section{REFERENCES}

Ballieux, R. E. (1984). (ed ) Psychoneuroimmunology and breakdown in adaptation: interactions within the central nervous system, the immune and endocrine systems. In Breakdown in Human Adaptation to 'Stress'. Towards a Multidisciplinary Approach, Vol. II. Part 3. pp. 732 739. Martınus N,jhoff: Dordrecht

Bartrop, R. W., Lazarus, L., Luckhurst, E., Kiloh, L. G. \& Penny, R. (1977). Depressed lymphocyte function after bereavement. Lancet $i$, $834-836$.

Bennette, G. (1969). Psychic and cellular aspects of isolation and identity imparment in cancer: a dialectıc of alienation. Annals of the New York Academy of Science 164, 352-363.

Besedovsky, H. O., del Rey, A. E., Sorkin, E., DaPrada, M., Burri, R. \& Honegger, C. (1983). The immune response evokes changes in brain noradrenergic neurons. Science 221, 564-566.

Black, S., Humphrey, J. H \& Niven, J. S F (1963). Inhibition of Mantoux reaction by direct suggestion under hypnosis. British Medical Journal i, 1649-1652

Bohus, B. (1984). Neuroendocrine interactions with brain and behaviour: a model for psychoneuroimmunology? In Breakdown in Human Adaptation in 'Stress', Vol. 2. (ed. R. E. Ballieux), pp. 638 652. Martinus Nijoff: Dordrecht.

Cooper, D. A. Duckett, M., Petts, V \& Penny, R. (1979). Corticosteroid enhancement of immunoglobulin synthesis by pokeweed mitogen stimulated human lymphocytes. Clinical and Experimental Immunology 37, 145-151.

Cowen, P G. \& Anderson, I M (1985). 5HT neuroendocrinology: changes during depressive illness and antidepressant drug treatment. In Biology of Depression, (ed. J. F W. Deakin), pp. 71-79. Gaskell Psychiatric Series, Royal College of Psychiatrists: London.

Farrant, J. \& Perez, M. (1987). Immunity and depression. In Modern Perspectives in the Psychiatry of Depression. (ed. J G. Howells), Brunner/Mazel: New York. (In the press.)

Fauc1, A. S. \& Dale, D. C. (1974). The effect of in vivo hydrocortisone on subpopulations of human lymphocytes. Journal of Clinical Investigation 53, 240-246.

Ghanta, V. K., Hiramoto, R. N., Solvason, H. B. \& Spector, N. H. (1985) Neural and environmental influences on neoplasia and conditioning of NK activity. Journal of Immunology 135, 848s852 s.

Jacobs, S. \& Ostfield, A. (1977). An epidemiological review of the mortality of bereavement. Psychosomatic Medicine 39, 344-357.
Knıght, J. G. (1982). Dopamine-receptor-stımulating antıbodies: a possible cause of schizophrena. Lancet ii, 1073-1075.

Kronfol, Z., Silva, J , Greden, J., Dembinskı, S., \& Carroll, B. J. (1982). Cell mediated immunity in melancholia. Psychosomatic Medicine 44, 304.

Kronfol, Z., Silva, J., Greden, J., Dembinski, S.. Gardner, R. \& Carroll, B. (1983). Impaired lymphocyte function in depressive illness. Life Sctences 33, 241-247.

Laudenslager, M L, Ryan, S. M., Drugan, R. C., Hyson, R. L. \& Maier, S. F. (1983). Coping and immunosuppression: inescapable but not escapable shock suppresses lymphocyte proliferation. Science 221, 568-570.

Linn, B. S , Linn, M W \& Jensen, J. (1982). Degree of depression and immune responsiveness. Psychosomaltc Medicine 44, 128129.

Meltzer, H. Y., Umberkoman-Wiita, B., Robertson, A., Tricou, B. J , Lowy, M. \& Perline, R. (1984). Effect of 5-hydroxytryptophan on serum cortisol levels in major affective disorders. I. Enhanced response in depression and mania. Archues of General Psychiatry 41, 366-374.

Munck, A., Gutre, P. M. \& Holbrook, N. J. (1984). Physiological functions of glucocorticoids in stress and their relation to pharmacological actions. Endocrine Reviews 5, 25-44.

Paykel, E. S, Myers, J. K., Dienelt, M. N, Klerman, G. L., Lindenthal, J. J. \& Pepper, M.P. (1969) Life events and depression: a controlled study. Archives of General Psychiatry 21, 753-760.

Rodnight, R. (1986). Peripheral biochemistry in schizophrenia. In The Psychopharmacology and Treatment of Schizophrenia. (ed. P. B Bradley \& S. R. Hirsch), pp. 1-26. Oxford Unıversity Press: Oxford.

Smith, G. R., McKenzie, J. M., Marmer, D. J. \& Steele, R. W. (1985). Psychological modulation of the human immune response to Varicella zoster. Archives of Internal Medicine 145, 2110$2 \ 12$.

Solomon, G. F., Levıne, S. \& Kraft, J. K (1968). Early experience and immunity. Nature 220, 821-822.

Solomon, G. F. \& Amkraut, A. A. (1981). Psychoneuroendocrinological effects on the immune response. Annual Reviews of Microbiology 35, 155-184.

Stein, M., Schiavı, R. C \& Camerino, M. (1976). Influence of brain and behavior on the immune system. Science 191, 435-440. 